Article

\title{
Investigating Light-Induced Processes in Covalent Dye-Catalyst Assemblies for Hydrogen Production
}

\author{
Sebastian Bold ${ }^{1,2,3}{ }^{\oplus}$, Tatiana Straistari ${ }^{1}$, Ana B. Muñoz-García ${ }^{4}\left({ }^{\circ}\right.$, Michele Pavone ${ }^{5}$, \\ Vincent Artero ${ }^{1}$, Murielle Chavarot-Kerlidou ${ }^{1, *}$ and Benjamin Dietzek 2,3,6,* \\ 1 Laboratoire de Chimie et Biologie des Métaux, Univ. Grenoble Alpes, CNRS, CEA IRIG, 17 rue des Martyrs, \\ F-38000 Grenoble, France; sebastian.bold@uni-jena.de (S.B.); tatiana.straistari@cea.fr (T.S.); \\ vincent.artero@cea.fr (V.A.) \\ 2 Institute of Physical Chemistry and Abbe Center of Photonics, Friedrich Schiller University Jena, \\ Helmholtzweg 4, 07743 Jena, Germany \\ 3 Department Functional Interfaces, Leibniz Institute of Photonic Technology Jena (Leibniz-IPHT), \\ Albert-Einstein-Straße 9, 07745 Jena, Germany \\ 4 Department of Physics "Ettore Pancini”, University of Naples Federico II, Complesso Universitario Monte \\ Sant'Angelo Via Cintia, 80126 Naples, Italy; anabelen.munozgarcia@unina.it \\ 5 Department of Chemical Sciences, University of Naples Federico II, Complesso Universitario Monte \\ Sant'Angelo Via Cintia, 80126 Naples, Italy; michele.pavone@gmail.com \\ 6 Center for Energy and Environmental Chemistry Jena (CEEC-Jena), Friedrich Schiller University Jena, \\ Philosophenweg 8, 07743 Jena, Germany \\ * Correspondence: murielle.chavarot-kerlidou@cea.fr (M.C.-K.); benjamin.dietzek@leibniz-ipht.de (B.D.)
}

Received: 17 October 2020; Accepted: 13 November 2020; Published: 18 November 2020

\begin{abstract}
The light-induced processes occurring in two dye-catalyst assemblies for light-driven hydrogen production were investigated by ultrafast transient absorption spectroscopy. These dyads consist of a push-pull organic dye based on a cyclopenta[1,2-b:5,4-b']dithiophene (CPDT) bridge, covalently linked to two different $\mathrm{H}_{2}$-evolving cobalt catalysts. Whatever the nature of the latter, photoinduced intramolecular electron transfer from the excited state of the dye to the catalytic center was never observed. Instead, and in sharp contrast to the reference dye, a fast intersystem crossing (ISC) populates a long-lived triplet excited state, which in turn non-radiatively decays to the ground state. This study thus shows how the interplay of different structures in a dye-catalyst assembly can lead to unexpected excited state behavior and might open up new possibilities in the area of organic triplet sensitizers. More importantly, a reductive quenching mechanism with an external electron donor must be considered to drive hydrogen production with these dye-catalyst assemblies.
\end{abstract}

Keywords: solar energy conversion; push-pull dye; intersystem crossing

\section{Introduction}

The conversion of solar energy into a storable fuel, such as hydrogen $\left(\mathrm{H}_{2}\right)$ through sunlight-driven water splitting, is currently the subject of intensive research efforts [1,2]. In that context, photosynthesis has been a great source of inspiration for molecular chemists, leading to the development of a wide variety of $\mathrm{H}_{2}$-evolving molecular dyads [3-13], inspired by the Photosystem I-Hydrogenase couple found in some hydrogen producing photosynthetic micro-organisms [14]. Recently, the first functional $\mathrm{H}_{2}$-evolving photocathodes integrating such molecular dyads were reported in the literature $[2,5,9,11,15]$, paving the way for solar fuels production in dye-sensitized photoelectrochemical cells. Our group contributed to the field with the design of covalent dye-catalyst assemblies based on $\mathrm{H}_{2}$-evolving cobalt catalysts $[12,13,16]$.

Understanding the excited state dynamics and electron transfer mechanisms in these systems is key to rationally improve their design and optimize their $\mathrm{H}_{2}$ evolution performances. We recently 
addressed the photoinduced processes at work with our first photoelectrocatalytically active dyad, thanks to a combination of classical spectroscopic techniques and transient absorption spectroelectrochemistry [17]. In the present study, we investigate the ultrafast excited state dynamics of two novel dye-catalyst assemblies specifically designed for improved photoelectrocatalytic hydrogen production in dye-sensitized photocathodes [18]. They comprise a push-pull organic dye (T2R) covalently assembled with two different $\mathrm{H}_{2}$-evolving cobalt catalysts: either the cobalt diimine-dioxime complex Cat2 [19] or the cobalt tetraazamacrocyclic catalyst Cat1 [20-22] (Figure 1). The metal-free dye structure relies on a triphenylamine (TPA) donor group functionalized by two protected carboxylic acid groups for its future anchoring onto semiconducting oxide-based electrodes and a cyanoacrylate/cyanoacrylamide acceptor group, separated by the electron-rich cyclopenta[1,2-b:5,4-b']dithiophene (CPDT) bridge. The latter is classically employed as a building block in organic photovoltaics or for dye-sensitized solar cell applications, thanks to its increased light absorption properties in the visible region of the spectrum $[23,24]$.
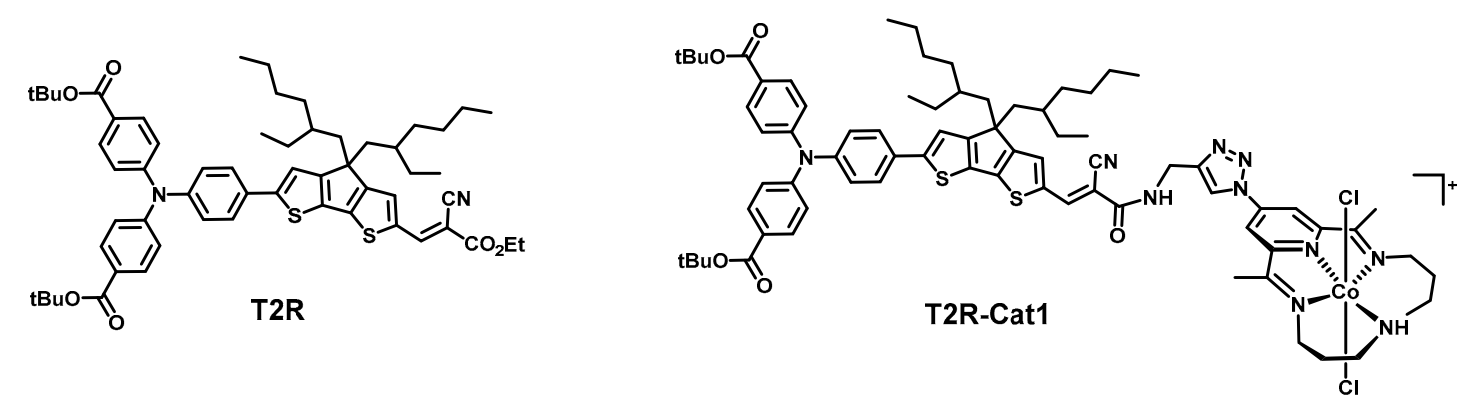

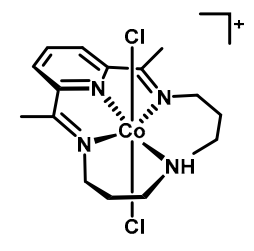

Cat1

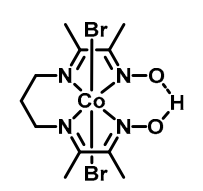

Cat2

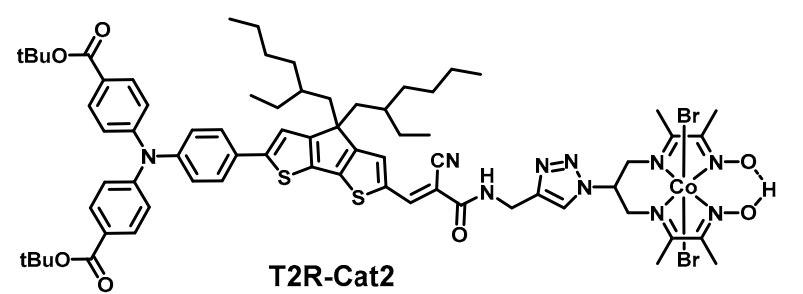

Figure 1. Structures of the dye T2R, catalysts Cat1 and Cat2, and dyads T2R-Cat1 and T2R-Cat2.

\section{Results}

\subsection{Steady-State Spectroscopy and Density Functional Theory (DFT) Calculations}

First insights into the light-induced processes in T2R, T2R-Cat1, and T2R-Cat2 are obtained from steady-state spectroscopy. In acetonitrile (ACN), the absorption spectra for all compounds show two main bands at 355 and around $495 \mathrm{~nm}$ (Figure 2). The band at $355 \mathrm{~nm}$ is assigned to the triphenylamine-centered transition, while the additional small band at $298 \mathrm{~nm}$ might be due to a localized transition on the bithiophene linker $[25,26]$. Below $320 \mathrm{~nm}$, the dyads additionally show contribution from the respective cobalt catalysts. In the visible region, the strong band at $495 \mathrm{~nm}$ results from the HOMO-LUMO transition with intramolecular charge-transfer (ICT) character from the TPA donor to the cyanoacrylate acceptor. Compared to the two dyads, the ICT band of T2R is slightly red-shifted $\left(\Delta \mathrm{E} \approx 200 \mathrm{~cm}^{-1}\right.$ ), which might stem from the stronger electron-withdrawing character of the ester terminal group in comparison with the amide, slightly increasing the push-pull character of the dye. As previously reported [23], the presence of the rigid CPDT unit strongly enhances the light-harvesting efficiency in the visible region $\left(\varepsilon\right.$ of $\left.60,300 \mathrm{M}^{-1} \cdot \mathrm{cm}^{-1}\right)$ compared to our previously-studied dyads relying on mono- or bis-thiophene units $\left(\varepsilon\right.$ of 31,800 and $38,600 \mathrm{M}^{-1} \cdot \mathrm{cm}^{-1}$, respectively) $[12,13,17,27]$. 

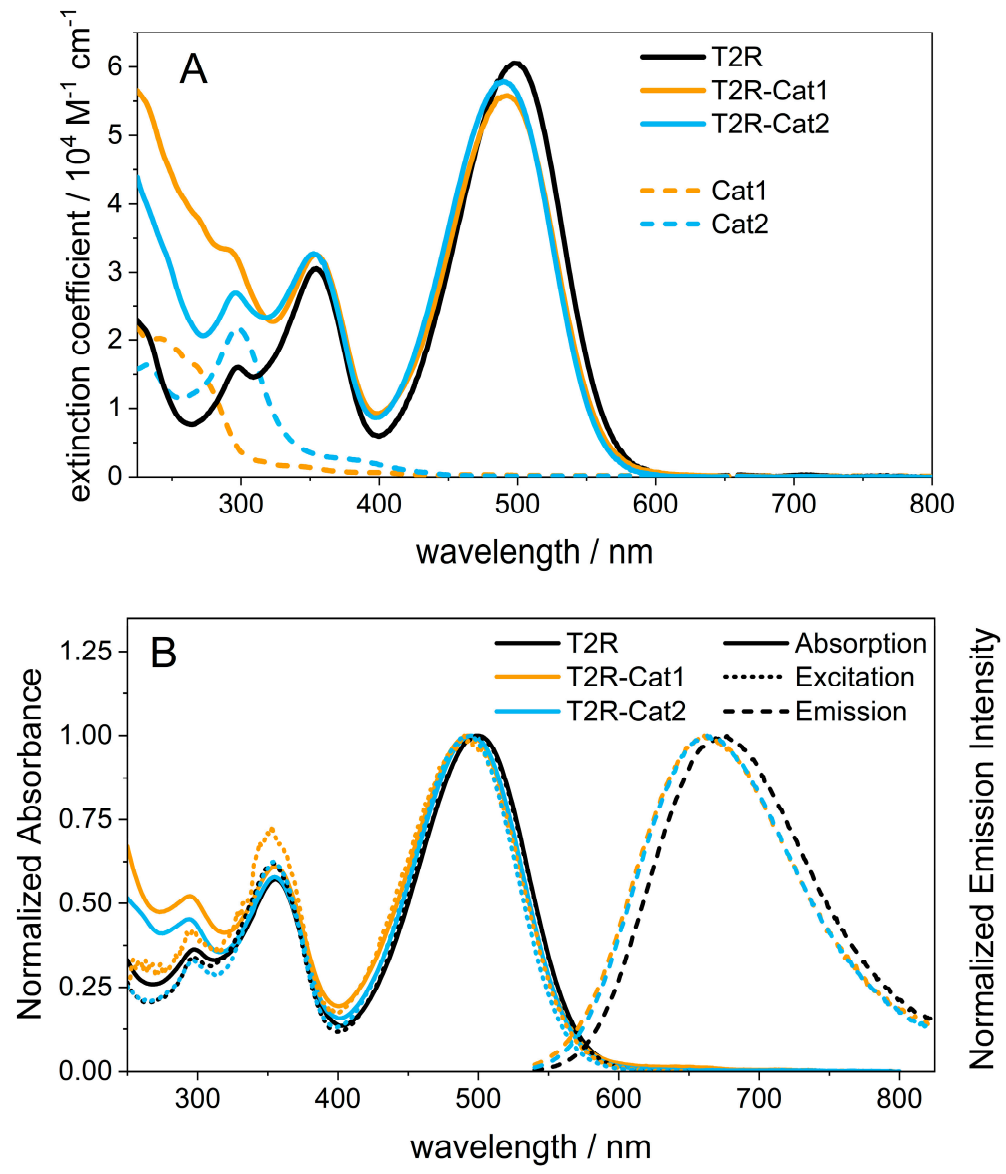

Figure 2. (A) UV-Vis absorption spectra of T2R, T2R-Cat1, T2R-Cat2, Cat1 and Cat2 recorded in acetonitrile. (B) Normalized absorption, emission and excitation spectra of T2R, T2R-Cat1 and T2R-Cat2 recorded in $\mathrm{MeOH}$. The emission quantum yield was 0.25 (T2R), 0.02 (T2R-Cat1) and 0.08 (T2R-Cat2).

The computed time-dependent (TD)-DFT vertical transition energies confirm the experimental assignments of the optical absorption spectra. The first bright transition (i.e., with a high oscillator strength value) at $472 \mathrm{~nm}$ for the T2R isolated dye corresponds to the HOMO-LUMO transition (ICT). The second transition at $331 \mathrm{~nm}$ corresponds to the HOMO-LUMO+1 transition localized on the TPA moiety (Supplementary Figure S1). These results are in full agreement with TD-DFT calculations previously reported for a structural analog of $\mathrm{T} 2 \mathrm{R}$, varying only by the nature of the acceptor group (dicyanovinyl unit instead of cyanoacrylate unit) [23]. For the T2R-Cat1 complex, the absorption transition energies are very similar to T2R, with the first ICT transition at $476 \mathrm{~nm}(\mathrm{HOMO} \rightarrow \mathrm{LUMO}+4)$ and the second (TPA) one at $335 \mathrm{~nm}(\mathrm{HOMO} \rightarrow \mathrm{LUMO}+6)$ (Supplementary Figure S2). The same electronic structure pattern is found for the T2R-Cat2 complex.

Considering their targeted application for hydrogen production under aqueous conditions, the electronic properties of the dyads were further studied in methanol $(\mathrm{MeOH})$, which is a protic solvent of higher polarity $\left(\mathrm{E}_{\mathrm{T}}{ }^{\mathrm{N}}=0.76\right)$ and viscosity $\left(\eta=0.59 \mathrm{mPa} \cdot \mathrm{s}^{-1}\right)$ than $\mathrm{ACN}\left(\mathrm{E}_{\mathrm{T}}{ }^{\mathrm{N}}=0.46\right.$ and $\eta=0.35 \mathrm{mPa} \cdot \mathrm{s}^{-1}$ ) $[28,29]$. The UV-Vis absorption spectra in $\mathrm{MeOH}$ (Supplementary Figures S2B and S3) are similar to those recorded in ACN. In particular, no significant shift of the ICT band is observed.

Upon excitation at $520 \mathrm{~nm}$, the compounds show emission, which is centered at $674 \mathrm{~nm}$ for T2R and $662 \mathrm{~nm}$ for the dyads (Figure 2B). As in the absorption spectra, the dyads show identical spectra while that of $T 2 \mathrm{R}$ is red-shifted $\left(\Delta \mathrm{E} \approx 281 \mathrm{~cm}^{-1}\right)$, which again is ascribed to the different nature of the acceptor group. All compounds show a large Stokes shift of $5100-5200 \mathrm{~cm}^{-1}$, caused by the stabilization of the charge-transfer state in the polar solvent $\mathrm{MeOH}$. While the emission quantum yield of $\mathrm{T} 2 \mathrm{R}$ is 0.25 , the dyads show much lower quantum yields, i.e., 0.02 (T2R-Cat1) and 0.08 (T2R-Cat2), corresponding 
to an emission quenching of $92 \%$ (T2R-Cat1) and $68 \%$ (T2R-Cat2), respectively. The covalent assembly with the cobalt catalysts seemingly opens up non-radiative decay pathways for the emissive state, leading to this pronounced emission quenching.

The emission excitation spectra show the same bands as the absorption spectra at 355 and $395 \mathrm{~nm}$, indicating that excitation in both the TPA and ICT bands leads to identical emission. For the dyads, there is a discrepancy between absorption and excitation spectra below $320 \mathrm{~nm}$ that is caused by the absorption band of the cobalt complexes, whose excitation does not lead to emission.

\subsection{Transient Absorption (TA) Spectroscopy of $T 2 R$}

To obtain further insights into the nature of the excited states and of the non-radiative decay induced by the covalent attachment to the catalytic center, we performed time-resolved transient absorption spectroscopy in $\mathrm{MeOH}$ with excitation at $480 \mathrm{~nm}$. The transient absorption spectra recorded for T2R at short delay times (Figure 3A) display a ground state bleach (GSB) centered at $490 \mathrm{~nm}$ and at $350 \mathrm{~nm}$, while an excited-state absorption (ESA) is observed above $615 \mathrm{~nm}$ and peaks around $690 \mathrm{~nm}$. Within 50 ps, the ESA undergoes a blue-shift via a transient double band structure with maxima at 575 and $656 \mathrm{~nm}$ to form a broad single ESA band with a maximum at $605 \mathrm{~nm}$. Simultaneously, a negative differential absorption band develops above $690 \mathrm{~nm}$ (Figure 3A). Once this spectral evolution is concluded, no further spectral shifts take place and an overall signal decay is observed. This decay, however, is not finished within the experimentally accessible time window of $1.6 \mathrm{~ns}$.

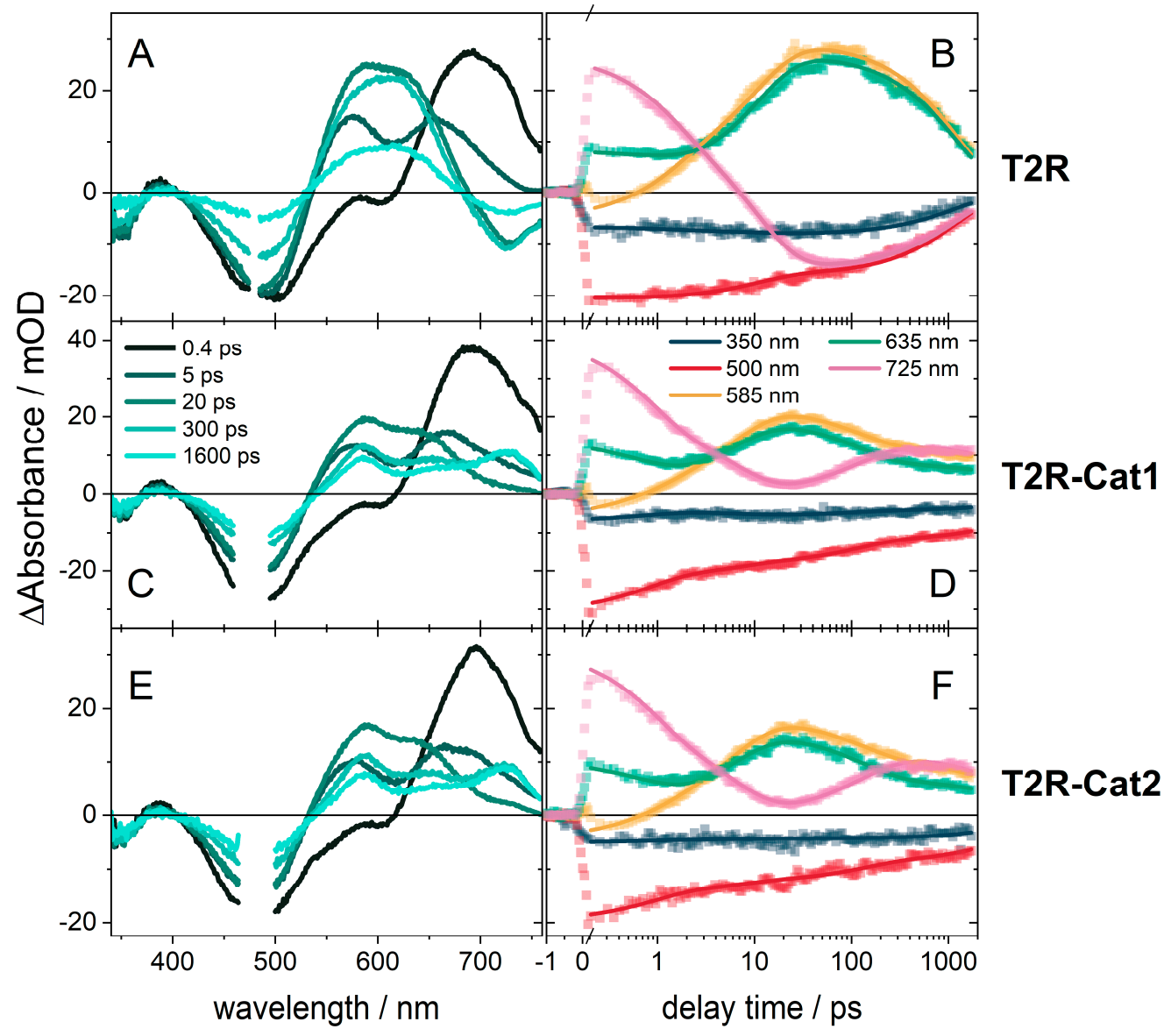

Figure 3. TA spectra at different pump-probe delays $(\mathbf{A}, \mathbf{C}, \mathbf{E})$ and kinetic traces $(\mathbf{B}, \mathbf{D}, \mathbf{F})$ of $\mathrm{T} 2 \mathrm{R}(\mathbf{A}, \mathbf{B})$, T2R-Cat1 (C,D) and T2R-Cat2 (E,F) in MeOH after excitation at $480 \mathrm{~nm}$. The solid lines in the kinetic traces are fits of the experimental data to the models presented in Figure 4. 


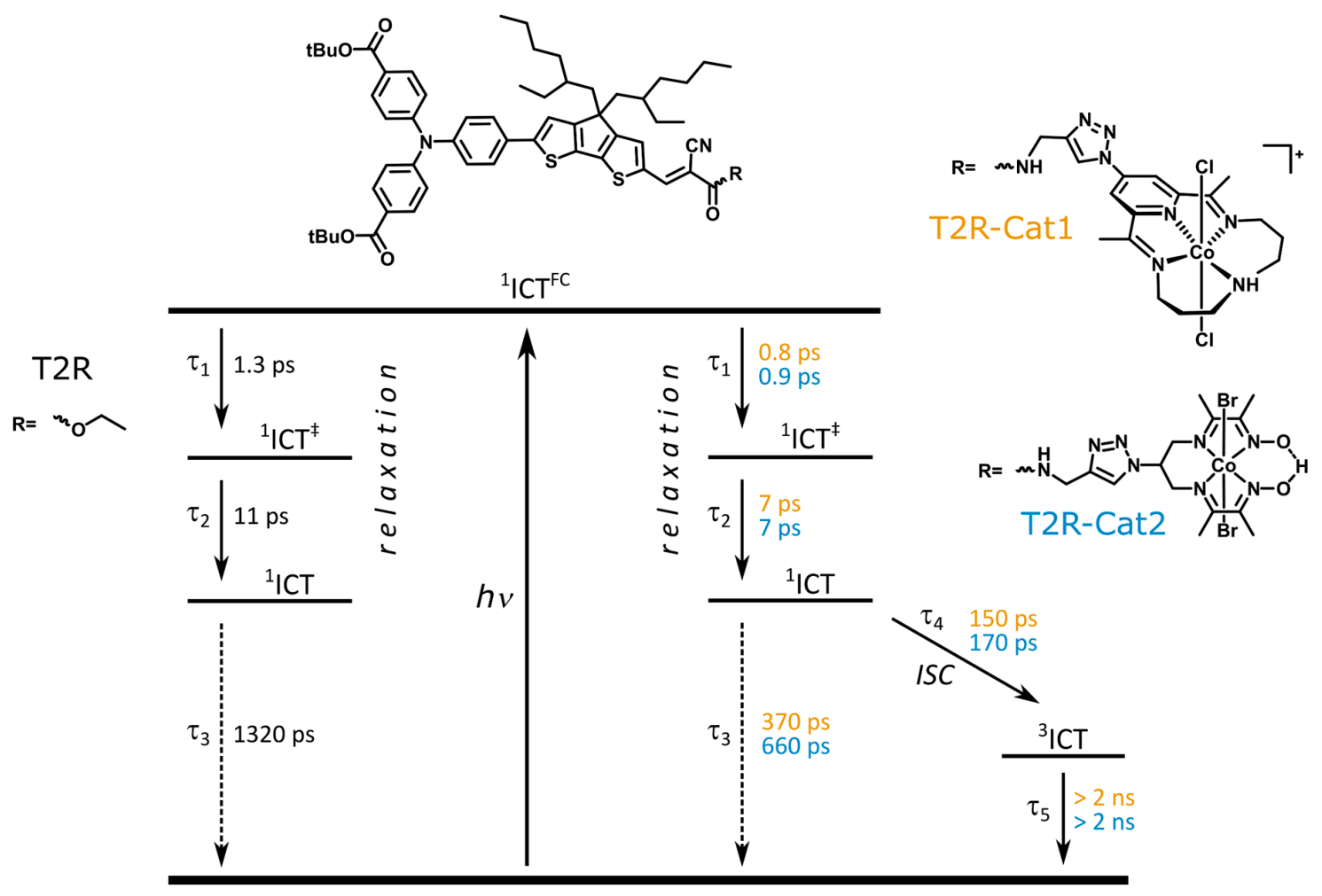

Figure 4. Photophysical model for the light-induced processes upon excitation at $480 \mathrm{~nm}$. The pathway to the triplet state by ISC $\left(\tau_{4}\right)$ is only open for the dyads. Dashed arrows indicate radiative transitions.

The spectral evolution observed for T2R can be rationalized with a model consisting of three consecutive processes starting from the initially excited ICT state, yielding the bleach at $480 \mathrm{~nm}$. The additional bleach at $350 \mathrm{~nm}$ is attributed to the GSB of the TPA absorption, supporting the calculations, which show this band to be a HOMO-LUMO+1 transition [23]. The negative differential absorption at $>690 \mathrm{~nm}$ is due to stimulated emission (SE). The red-shift compared to the steady-state emission measurements, where the maximum was located at $674 \mathrm{~nm}$, can be explained by an overlap of the negative SE band with the positive ESA band. A sequential three-component exponential fit satisfyingly fits the data and gives characteristic time constants associated with the processes of $\tau_{1}=1.3$, $\tau_{2}=11$ and $\tau_{3}=1320$ ps (Table 1, species-associated spectra in Figure 5).

Table 1. Characteristic time constants of light-induced processes upon excitation at $480 \mathrm{~nm}$. The corresponding rates are given in Table $\mathrm{S} 2$.

\begin{tabular}{cccccc}
\hline \multirow{2}{*}{-} & \multicolumn{5}{c}{ Time Constants $^{\mathbf{1}} / \mathbf{p s}$} \\
\cline { 2 - 6 } & $\boldsymbol{\tau}_{\mathbf{1}}$ & $\boldsymbol{\tau}_{\mathbf{2}}$ & $\boldsymbol{\tau}_{\mathbf{3}}$ & $\boldsymbol{\tau}_{\mathbf{4}}$ & $\boldsymbol{\tau}_{\mathbf{5}}$ \\
\hline T2R & 1.3 & 11 & 1320 & & \\
T2R-Cat1 & 0.8 & 7 & 370 & 150 & $>>2 \mathrm{~ns}$ \\
T2R-Cat2 & 0.9 & 7 & 660 & 170 & $>>2 \mathrm{~ns}$ \\
\hline \multicolumn{7}{c}{${ }^{1} \tau_{\mathrm{n}}=1 / \mathrm{k}_{\mathrm{n}}}$.
\end{tabular}

Based on the spectral evolution associated with the first two processes, i.e., a blue-shift of ESA with no concurrent GSB decay, they can be assigned to relaxation of the initially populated hot state $\mathrm{ICT}^{\mathrm{FC}}$ via a partly relaxed ICT ${ }^{\ddagger}$ state. The observed red-shift of the SE, from the initial dip at $600 \mathrm{~nm}$ to the negative band at $>690 \mathrm{~nm}$, further supports this assignment. The exact nature of these relaxation processes is not clear in this class of push-pull dyes [30-33]. Quite generally, it is ascribed to a solvation process in response to the photoinduced intramolecular shift of electron density [33], coupled to a relaxation cascade through molecular motion such as flattening and rotation around bonds [30]. 
In addition, the coexistence of various conformers in solution might further complicate the assignment of the process to molecular degrees of freedom.

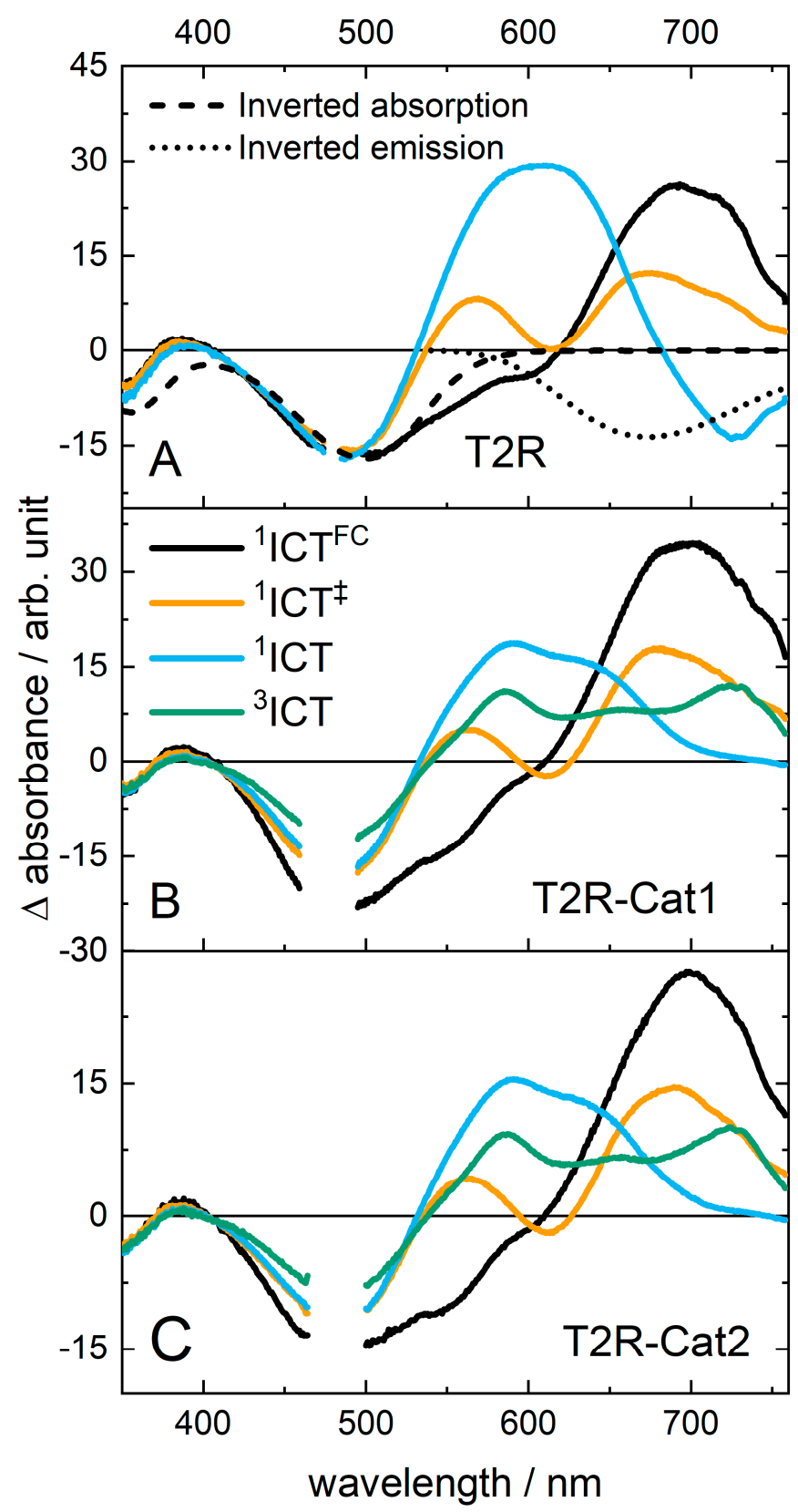

Figure 5. Species-associated spectra obtained by fitting the TA data of (A) T2R, (B) T2R-Cat1 and (C) T2R-Cat2 obtained at $480 \mathrm{~nm}$ excitation with the model shown in Figure 4 . The dashed and dotted lines in the first panel show the inverted and scaled steady-state absorption and emission spectra.

To this end, we computed the DFT minimum energy structures for four conformations for the T2R dye, considering different relative positions of the CPDT system, the CN, and the $\mathrm{CO}$ moieties (Figure 6, Table 2). These four conformations were found to be very close in energy with energy differences in the ground state below $0.1 \mathrm{eV}(<2.3 \mathrm{kcal} / \mathrm{mol})$, meaning all conformers are likely present in solution. The TD-DFT vertical electronic transitions computed were scarcely affected by the different dye conformations with differences below $2 \mathrm{~nm}$ (Table 2). However, the molecular dynamics and the interconversion between the different conformers, not explored here, could be responsible for the complex relaxation processes in the excited state. In $\mathrm{MeOH}$, the cooling processes are slowed down in comparison with measurements 
performed in ACN (Supplementary Figure S4), where the cooling process could be fitted with a single component with $\tau=1$ ps. This can be explained by the higher viscosity of $\mathrm{MeOH}$, which slows down the relaxation processes involving major molecular motion, as observed before for similar push-pull dyes $[17,30]$. This effect could be further increased by hydrogen bonds formed by $\mathrm{MeOH}$, which ACN does not. The third process is the return to the ground state of the thermalized excited state ${ }^{1} \mathrm{ICT}$, reflected in a concerted decay of GSB, ESA, and SE. This excited state behavior is in line with that observed previously for a related compound with a single thiophene linker [17,34].
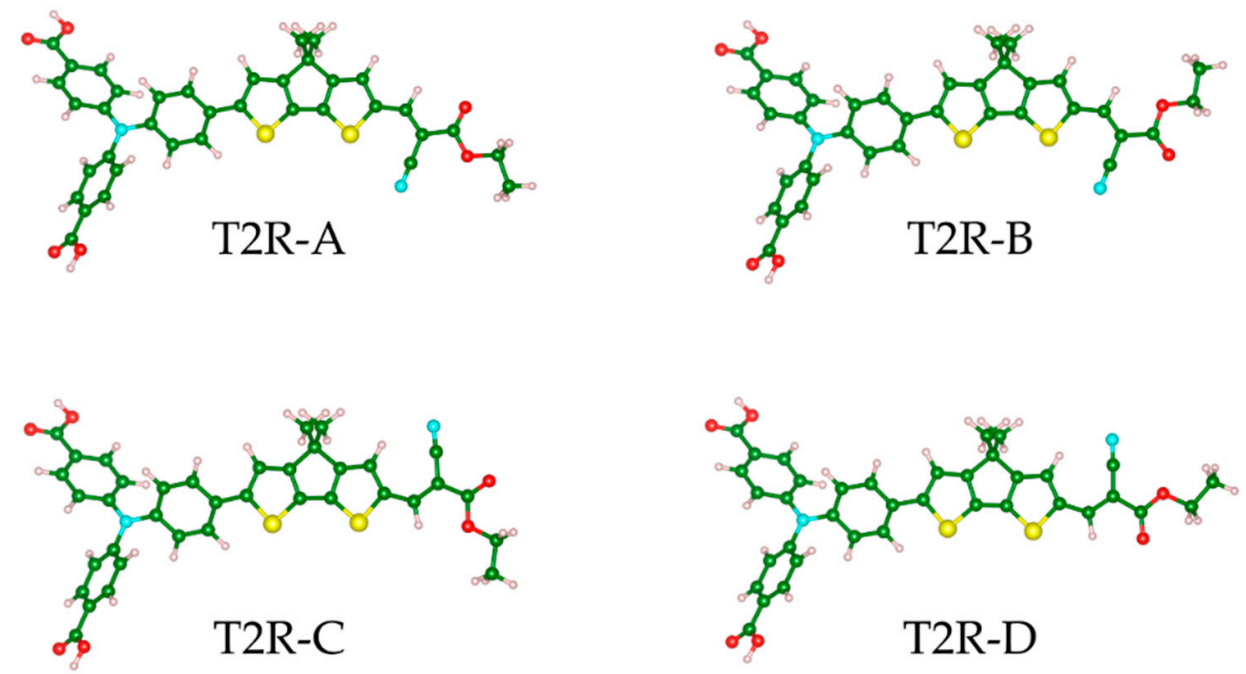

Figure 6. Minimum energy structures of four conformations for the T2R dye obtained by DFT calculations.

Table 2. Relative energies ( $\triangle \mathrm{E})$ at the B3LYP level of theory, including zero-point vibrational energies within the harmonic approximation, and vertical transition energies at the CAM-B3LYP level of theory, including the acetonitrile solvent medium via the PCM, with the oscillator strengths given in parenthesis. For the labelling, refer to Figure 6.

\begin{tabular}{ccccc}
\hline & T2R-A & T2R-B & T2R-C & T2R-D \\
\hline$\Delta \mathrm{E} / \mathrm{eV}$ & 0.014 & 0.107 & 0.084 & 0.0 \\
$\lambda(\mathrm{ICT}) / \mathrm{nm}$ & $473(1.793)$ & $472(1.784)$ & $471(1.900)$ & $472(1.929)$ \\
$\lambda(\mathrm{TPA}) / \mathrm{nm}$ & $331(0.618)$ & $331(0.619)$ & $331(0.615)$ & $331(0.616)$ \\
\hline
\end{tabular}

\subsection{Transient Absorption Spectroscopy of the Dyads}

In the dyads (Figure 3B,C), the initial TA spectra are identical to those of T2R (Supplementary Figure S5a) and the processes taking place within the first 20 ps after photoexcitation are similar in timescale and spectral changes to T2R. They are therefore attributed to the relaxation of the initially excited hot singlet state of the dye moiety to the thermalized singlet excited state ${ }^{1} \mathrm{ICT}$. This state shows a more pronounced double band structure in the ESA than T2R, with maxima at $589 \mathrm{~nm}$ and $640 \mathrm{~nm}$, while the absence of the negative SE band above $695 \mathrm{~nm}$ is in line with the reduced emission quantum yield of the dyads when compared to T2R. In contrast to T2R, an additional spectral evolution is observed within ca. 300 ps, with a decrease in intensity of the ESA and the formation of a long-lived species, characterized by a double band absorption at 590 and $725 \mathrm{~nm}$. This new band persists up to the longest experimentally accessible delay times (1.6 ns), while a partial decay of the ESA band around $600 \mathrm{~nm}$ continues. The bleach at $500 \mathrm{~nm}$ shows less decay for the dyads compared to T2R ( $33 \%$ remaining signal for the dyads and $20 \%$ for the dye). The characteristic absorption observed at the end of the accessible time window (1.6 ns) is identical for both dyads (Supplementary Figure S5b), irrespective of the nature of the catalytic center. Furthermore, it does not match the spectra of the $\mathrm{Co}^{\text {II }}$ states of the catalysts, which show maxima at 595 and $512 \mathrm{~nm}$ for Cat1 and Cat2, respectively (Supplementary Figure S6) [17,20,35]. Additionally, the extinction coefficients of the optical transitions 
on the cobalt complex are an order of magnitude lower than those of the dye, while the band observed in the TA spectrum shows a similar intensity to the other dye-based bands. These observations lead us to discard a photoinduced electron transfer process to the catalyst and formation of a charge-transfer species with the electron localized on the cobalt complex ( $\mathrm{Co}^{\mathrm{II}}$ state), in spite of its thermodynamic feasibility (see Supplementary Table S1). Instead, we propose that a triplet state forms by ${ }^{1} \mathrm{ICT} \rightarrow{ }^{3} \mathrm{ICT}$ intersystem crossing. Bi- and oligothiophenes are known to undergo fast ISC on the timescale of $50 \mathrm{ps}$ to $1 \mathrm{~ns}$ [36,37], reminiscent of the behavior observed here for the CPDT bridge of our push-pull dye system. The extinction coefficients of the oligothiophene triplet states are also in the same order of magnitude as that of T2R $\left(\approx 38,000 \mathrm{M}^{-1} \mathrm{~cm}^{-1}\right.$ for the oligothiophenes, $\approx 55,000 \mathrm{M}^{-1} \mathrm{~cm}^{-1}$ for T2R and T2R-based dyads) [37], in line with the observed similar intensity of the ESA band at $725 \mathrm{~nm}$ compared to the GSB. The triplet absorption of pure oligothiophenes is observed at higher energies (2.7 eV corresponding to $460 \mathrm{~nm}$ for terthiophene) [37] than those observed here. However, the CPDT structure is part of an extended conjugated charge-transfer system which can have a strong effect on the excited state energies. In addition, the long lifetime observed for this species is in full agreement with a triplet state, which generally show longer lifetimes than singlet states due to the spin-forbidden nature of the decay to the ground state. Finally, the decay of ESA signal between 540 and $690 \mathrm{~nm}$ observed after $300 \mathrm{ps}$ is attributed to direct decay of ${ }^{1} \mathrm{ICT}$ to the ground state, analogous to the situation in T2R.

Thus, we assume the model shown in Figure 4: following the initial relaxation processes $\left(k_{1}\right.$ and $\left.\mathrm{k}_{2}\right)$, the resulting singlet ICT excited state can decay directly to the ground state $\left(\mathrm{k}_{3}\right)$ as well as, in the case of the dyads, undergo ISC to form the triplet state $\left(\mathrm{k}_{4}\right)$, which in turn decays back to the ground state $\left(k_{5}\right)$. When fitting the TA data with this model, the direct decay $\left(k_{3}\right)$ was not fitted, probably due to the low spectral amplitude and low number of recorded points. However, from the spectral evolution after $300 \mathrm{ps}$, which shows further signal decay at $500 \mathrm{~nm}$ and around $600 \mathrm{~nm}$, i.e., at the position of GSB and ESA of the ${ }^{1} \mathrm{ICT}$ state, the presence of this direct decay must be deduced. We therefore eliminated the contribution of the ${ }^{3} \mathrm{ICT}$ state from the TA spectra by subtracting the spectrum recorded at $300 \mathrm{ps}$ $(\varepsilon=\varepsilon(\lambda, \Delta \mathrm{t})-\varepsilon(\lambda, 300 \mathrm{ps}))$. The spectra thus obtained showed the inverted TA spectrum of the ${ }^{1} \mathrm{ICT}$ state, validating the assignment of direct ${ }^{1}$ ICT decay to this spectral evolution (Figures S7 and S8). The decay at the maximum at $600 \mathrm{~nm}$ was fitted with a monoexponential decay to obtain the values for $\tau_{3}$ (370 ps for T2R-Cat 1 and $660 \mathrm{ps}$ for T2R-Cat2), which were then fixed in the global fit to the presented model to yield the species-associated spectra and rates of the different processes (Figure 5B,C, Table 1). The obtained rate for the direct decay of the singlet excited state to the ground state is double that observed for T2R. We previously observed a similar trend for a related assembly with an organic dye and cobalt complex, where the excited state lifetime decreased from 1840 to 470 ps [17]. We proposed Dexter energy transfer to short-lived cobalt-centered states as a possible cause for the reduction in lifetime, an explanation that can equally hold true for the compounds studied here. The rate of ISC was determined to be $\mathrm{k}_{4}=6.5 \times 10^{9} \mathrm{~s}^{-1}\left(\tau_{4}=150 \mathrm{ps}\right)$ and $\mathrm{k}_{4}=5.8 \times 10^{9} \mathrm{~s}^{-1}\left(\tau_{4}=170 \mathrm{ps}\right)$ for T2R-Cat1 and T2R-Cat2, respectively, while the lifetime of the triplet state was $\tau_{5}>2 \mathrm{~ns}$, reflecting the long-lived signal observed.

\section{Discussion}

The ISC rate observed in our systems is comparable to literature values for bi- and terthiophene (50-135 ps) [37,38]. The extremely fast ISC rates for bithiophene are explained in the literature by a very small energy difference of the $S_{1}$ and $T_{2}$ state [36]. In general, the sulfur atom plays a role in the fast ISC processes in thiophenes due to its high spin-orbit coupling factor [39]. However, as ISC is absent in T2R despite the identical dye structure as in the dyads, the bithiophene structure cannot be the sole source of the ISC and the explanations offered in the literature likely do not fully account for the fast ISC in our systems. In particular, those invoking the population of higher vibrational states in the singlet excited state do not apply in this case, as all systems show identical initial kinetics involving ultrafast relaxation to a thermalized singlet excited state that is finished before ISC is observable. The obvious difference in the dyads in comparison to the T2R is, however, the presence of the cobalt 
complex. In the literature, descriptions of ISC induced by cobalt in binary systems are limited (to the best of our knowledge) to the influence of the paramagnetic nature of $\mathrm{Co}^{\mathrm{II}}$ ions [40,41]. However, the cobalt complexes in this study are diamagnetic $\mathrm{Co}^{\mathrm{III}}$ complexes. Instead, alternative pathways must be considered, most probably involving higher energy states on the cobalt complexes. In fact, there are several such states between the HOMO and LUMO energy levels of the dye, which could play a role in the observed ISC (Supplementary Figure S2). The latter was tentatively investigated by density functional calculations, unfortunately without success.

In the literature on heavy-atom free triplet sensitizers, there are examples of radical pair intersystem crossing (RP-ISC), where after charge transfer an electron changes its spin to go from the ${ }^{1} \mathrm{CT}$ state to the ${ }^{3} \mathrm{CT}$ state via hyperfine coupling, which then relaxes to a localized triplet state [42]. In our case, it would be thermodynamically feasible for the excited electron to transfer to a higher state on the cobalt and back to the dye, accompanied by a spin change. However, RP-ISC alone occurs on time scales of nanoseconds and is therefore much slower than the ISC observed in the T2R dyads [43-45]. A different approach is the use of spin convertors-most prominently fullerenes-that, after energy transfer from the chromophore to the spin convertor, undergo ISC to yield the triplet state on the spin convertor, which then by a second energy transfer step relaxes to yield the triplet state localized on the chromophore [46-48]. In our case, the Co complex could act as a spin convertor after electron transfer since ISC has been observed to occur on a ps time scale in the ground state of Co complexes [49] and $<1 \mathrm{ps}$ in the excited state [50], and thus could be much faster than the ISC rates observed here. If the ISC and back CT to the dye are much faster than the CT to the complex, the latter would be the gating process and there would be no accumulation of the CT state with the electron localized on the Co complex, explaining why this species was not observed in the experiment.

\section{Materials and Methods}

Cat1 [20] and Cat2 [51] were prepared according to previously reported procedures. Detailed synthetic procedures for T2R, T2R-Cat1, and T2R-Cat2 are reported elsewhere [18]. For T2R-Cat2, the copper-catalyzed azide-alkyne cycloaddition (CuAAC) coupling we previously reported for related dyads based on push-pull dyes $[12,13]$ was employed. The synthesis of T2R-Cat1 relies on a CuAAC coupling between 4-azido-2,6-diacetylpyridine and the alkyne derivative of T2R, followed by the template-directed synthesis of the macrocyclic catalytic center. Spectroscopic-grade solvents (Sigma Aldrich, UV-Vis grade or better) were used for all the spectroscopic characterizations.

Steady-state UV-vis absorption spectroscopy: Steady-state absorption spectra were recorded on a Jasco V780 spectrophotometer or a Specord S600 (Analytik Jena) in $1 \mathrm{~cm}$ cuvettes.

Steady-state emission spectroscopy: Emission spectra were measured on an Edinburgh FLS980 emission spectrofluorometer in a $1 \mathrm{~cm}$ cuvette at $90^{\circ}$ angle. The solutions were prepared to have an absorbance of 0.05 at the excitation wavelength. Quantum yields were determined on the same instrument equipped with an integrating sphere, with solution at 0.1 absorbance at the excitation wavelength.

Transient absorption spectroscopy: The setup for femtosecond transient absorption measurements has been previously described [10]. An amplified Ti:Sapphire laser (Legend, Coherent Inc) produced the $800 \mathrm{~nm}$ fundamental beam which was split into two beams. One of the beams was used to pump an optical-parametric amplifier (TOPAS-C), whose output was spectrally centered at $480 \mathrm{~nm}$ and used as pump pulses for the pump-probe experiments. The pump pulses were typically set to $0.5 \mu \mathrm{J}$ per pulse. To achieve the pump-probe delay of $2 \mathrm{~ns}$, the pump beam was directed over a delay line. The supercontinuum used as probe pulse was generated by passing the second beam of the fundamental $800 \mathrm{~nm}$ through a $\mathrm{CaF}_{2}$ window, with probe intensities falling into the range of hundred $\mathrm{nJ}$. The probe light was split into two beams, one of which was focused through the sample, while the other served as reference. The probe and reference beams were detected by a double-stripe diode array and converted into differential absorption signals using a commercially available detection system (Pascher Instruments $\mathrm{AB}$, Lund Sweden). The recorded data were corrected for the chirp and globally fitted using a sum of three exponential. During the fitting, the pulse overlap region of $\pm 200 \mathrm{fs}$ was excluded to 
avoid contributions from coherent artefacts [52]. The measurements were performed in $1 \mathrm{~mm}$ cuvettes on solutions prepared to have an absorbance of 0.3 at the excitation wavelength $(480 \mathrm{~nm})$.

Computational details: All the calculations were carried out with the Gaussian16 suite of quantum chemistry programs [53]. The electronic ground state and the vertical excitation energies of T2R, T2R-Cat1, and T2R-Cat2 complexes have been characterized with DFT [54] and TD-DFT [55] approaches, respectively. Structural optimizations were carried out with the B3LYP hybrid density functional [56] and the Def2TZVP [57] basis set for C, H, O, N, and S atoms, and the SDD ECP and basis for the Co atom [58]. Because the excitation energies have a strong character of intramolecular charge transfer, we recall to the CAM-B3LYP level of theory with the same basis set for all the TD-DFT calculations [59]. In all the calculations, we have included the Acetonitrile solvent medium via the polarizable continuum model (PCM) [60].

\section{Conclusions}

The photoinduced processes at work in two novel dye-catalyst assemblies designed for hydrogen production in dye-sensitized photocathodes have been investigated by steady-state and ultrafast spectroscopic techniques. Comprehensive studies on the excited state dynamics of push-pull organic dyes are not common in the literature [30-33,61-63]. Compared to metallo-organic photosensitizers such as $\mathrm{Ru}(\mathrm{bpy})_{3}{ }^{2+}$, various conformers indeed coexist in solution for these structures, increasing the number of potential relaxation pathways, thus rendering the photophysical analysis much more complex. The results presented here nevertheless highlight that appending a cobalt-based catalytic unit to a push-pull organic dye strongly affects its photophysical properties. In particular, the quenching of the dye emission within the dyad is not the signature of a photoinduced intramolecular electron transfer process to the catalytic center. Instead, a new non-radiative relaxation pathway is opened, involving intersystem crossing to a long-lived triplet excited state. Although the mechanism behind that is still unclear, this opens new perspectives of application for this family of dyads as organic triplet sensitizers. This study also provides key information regarding light-driven hydrogen evolution with these dye-catalyst assemblies, i.e., an initial reductive quenching mechanism with the electron donor is required for catalysis to occur.

Supplementary Materials: The following are available online at http://www.mdpi.com/2073-4344/10/11/1340/s1. Figure S1: Frontier molecular orbitals of T2R, Figure S2: Frontier molecular orbitals of T2R-Cat1, Figure S3: UV-Vis absorption spectra of T2R, T2R-Cat1, and T2R-Cat2 in MeOH, Figure S4: TA spectra and species-associated spectra of T2R in ACN, Figure S5: Transient absorption spectra at $0.4 \mathrm{ps}$ and $1600 \mathrm{ps}$ time delay in MeOH, Figure S6: UV-Vis spectroelectrochemical spectra of T2R-Cat1, Figure S7: Differential TA spectra of T2R-Cat1 in MeOH of the direct decay and monoexponential fit, Figure S8: Differential TA spectra of T2R-Cat2 in MeOH of the direct decay and monoexponential fit, Table S1: Photophysical and redox properties of Cat1, Cat2, T2R, T2R-Cat1, and T2R-Cat2, Table S2: Rates and characteristic time constants of excited-state processes.

Author Contributions: Conceptualization, B.D. and M.C.-K.; methodology, S.B., B.D., M.P., and A.B.M.-G; validation, S.B.; formal analysis, S.B., M.P., and A.B.M.-G; investigation, S.B., T.S., M.P., and A.B.M.-G.; resources, B.D., M.C.-K., and V.A.; writing-original draft preparation, S.B.; writing-review and editing, M.C.-K., B.D., and S.B.; visualization, S.B.; funding acquisition, B.D., M.C.-K., and V.A. All authors have read and agreed to the published version of the manuscript.

Funding: This research was supported by the European Commission's Seventh Framework Program (FP7/2007-2013) under grant agreement $\mathrm{n}^{\circ} 306398$ (FP7-IDEAS-ERC, Project Photocat $\mathrm{H}_{2}$ ode), the French National Research Agency in the framework of the "Investissements d'avenir" program (ANR-15-IDEX-02, Labex ARCANE and CBH-EURGS, ANR-17-EURE-0003) and the Franco-German University.

Acknowledgments: We thank Yves Carstensen and Maria Sittig for their help in measuring the emission quantum yields. We thank Jens Uhlig for providing us with his data analysis software used for fitting the TA data.

Conflicts of Interest: The authors declare no conflict of interest. The funders had no role in the design of the study; in the collection, analyses, or interpretation of data; in the writing of the manuscript, or in the decision to publish the results. 


\section{References}

1. Walter, M.G.; Warren, E.L.; McKone, J.R.; Boettcher, S.W.; Mi, Q.; Santori, E.A.; Lewis, N.S. Solar Water Splitting Cells. Chem. Rev. 2010, 110, 6446-6473. [CrossRef]

2. Dalle, K.E.; Warnan, J.; Leung, J.J.; Reuillard, B.; Karmel, I.S.; Reisner, E. Electro- and Solar-Driven Fuel Synthesis with First Row Transition Metal Complexes. Chem. Rev. 2019, 119, 2752-2875. [CrossRef] [PubMed]

3. Pfeffer, M.G.; Schäfer, B.; Smolentsev, G.; Uhlig, J.; Nazarenko, E.; Guthmuller, J.; Kuhnt, C.; Wächtler, M.; Dietzek, B.; Sundström, V.; et al. Palladium versus Platinum: The Metal in the Catalytic Center of a Molecular Photocatalyst Determines the Mechanism of the Hydrogen Production with Visible Light. Angew. Chem. Int. Ed. 2015, 54, 5044-5048. [CrossRef] [PubMed]

4. Dempsey, J.L.; Brunschwig, B.S.; Winkler, J.R.; Gray, H.B. Hydrogen Evolution Catalyzed by Cobaloximes. ACC Chem. Res. 2009, 42, 1995-2004. [CrossRef] [PubMed]

5. Shan, B.; Das, A.K.; Marquard, S.; Farnum, B.H.; Wang, D.; Bullock, R.M.; Meyer, T.J. Photogeneration of hydrogen from water by a robust dye-sensitized photocathode. Energy Environ. Sci. 2016, 9, 3693-3697. [CrossRef]

6. Mengele, A.K.; Kaufhold, S.; Streb, C.; Rau, S. Generation of a stable supramolecular hydrogen evolving photocatalyst by alteration of the catalytic center. Dalton Trans. 2016, 45, 6612-6618. [CrossRef]

7. Luo, G.-G.; Pan, Z.-H.; Lin, J.; Sun, D. Tethered sensitizer-catalyst noble-metal-free molecular devices for solar-driven hydrogen generation. Dalton Trans. 2018, 47, 15633-15645. [CrossRef]

8. Braumüller, M.; Schulz, M.; Sorsche, D.; Pfeffer, M.; Schaub, M.; Popp, J.; Park, B.-W.; Hagfeldt, A.; Dietzek, B.; Rau, S. Synthesis and characterization of an immobilizable photochemical molecular device for H2-generation. Dalton Trans. 2015, 44, 5577-5586. [CrossRef]

9. Põldme, N.; O’Reilly, L.; Fletcher, I.; Portoles, J.; Sazanovich, I.V.; Towrie, M.; Long, C.; Vos, J.G.; Pryce, M.T.; Gibson, E.A. Photoelectrocatalytic $\mathrm{H}_{2}$ evolution from integrated photocatalysts adsorbed on NiO. Chem. Sci. 2019, 10, 99-112. [CrossRef]

10. Karnahl, M.; Kuhnt, C.; Ma, F.; Yartsev, A.; Schmitt, M.; Dietzek, B.; Rau, S.; Popp, J. Tuning of Photocatalytic Hydrogen Production and Photoinduced Intramolecular Electron Transfer Rates by Regioselective Bridging Ligand Substitution. ChemPhysChem 2011, 12, 2101-2109. [CrossRef]

11. Shan, B.; Nayak, A.; Brennaman, M.K.; Liu, M.; Marquard, S.L.; Eberhart, M.S.; Meyer, T.J. Controlling Vertical and Lateral Electron Migration Using a Bifunctional Chromophore Assembly in Dye-Sensitized Photoelectrosynthesis Cells. J. Am. Chem. Soc. 2018, 140, 6493-6500. [CrossRef] [PubMed]

12. Windle, C.D.; Massin, J.; Chavarot-Kerlidou, M.; Artero, V. A protocol for quantifying hydrogen evolution by dye-sensitized molecular photocathodes and its implementation for evaluating a new covalent architecture based on an optimized dye-catalyst dyad. Dalton Trans. 2018, 47, 10509-10516. [CrossRef] [PubMed]

13. Kaeffer, N.; Massin, J.; Lebrun, C.; Renault, O.; Chavarot-Kerlidou, M.; Artero, V. Covalent Design for Dye-Sensitized H2 -Evolving Photocathodes Based on a Cobalt Diimine-Dioxime Catalyst. J. Am. Chem. Soc. 2016, 138, 12308-12311. [CrossRef] [PubMed]

14. McTavish, H. Hydrogen Evolution by Direct Electron Transfer from Photosystem I to Hydrogenases. J. Biochem. 1998, 123, 644-649. [CrossRef] [PubMed]

15. Gibson, E.A. Dye-sensitized photocathodes for H2 evolution. Chem. Soc. Rev. 2017, 46, 6194-6209. [CrossRef]

16. Lyu, S.; Massin, J.; Pavone, M.; Muñoz-García, A.B.; Labrugère, C.; Toupance, T.; Chavarot-Kerlidou, M.; Artero, V.; Olivier, C. H2-Evolving Dye-Sensitized Photocathode Based on a Ruthenium-Diacetylide/Cobaloxime Supramolecular Assembly. ACS Appl. Energy Mater. 2019, 2, 4971-4980. [CrossRef]

17. Bold, S.; Zedler, L.; Zhang, Y.; Massin, J.; Artero, V.; Chavarot-Kerlidou, M.; Dietzek, B. Electron transfer in a covalent dye-cobalt catalyst assembly-a transient absorption spectroelectrochemistry perspective. Chem. Commun. 2018, 54, 10594-10597. [CrossRef]

18. Bold, S.; Massin, J.; Giannoudis, E.; Koepf, M.; Artero, V.; Dietzek, B.; Chavarot-Kerlidou, M. Spectroscopic investigations provide a rational for the hydrogen-evolving activity of dye-sensitized photocathodes based on a cobalt tetraazamacrocyclic catalyst. 2020. Submitted for publication.

19. Kaeffer, N.; Chavarot-Kerlidou, M.; Artero, V. Hydrogen evolution catalyzed by cobalt diimine-dioxime complexes. Acc. Chem. Res. 2015, 48, 1286-1295. [CrossRef] 
20. Varma, S.; Castillo, C.E.; Stoll, T.; Fortage, J.; Blackman, A.G.; Molton, F.; Deronzier, A.; Collomb, M.-N. Efficient photocatalytic hydrogen production in water using a cobalt(III) tetraaza-macrocyclic catalyst: Electrochemical generation of the low-valent $\mathrm{Co}(\mathrm{I})$ species and its reactivity toward proton reduction. Phys. Chem. Chem. Phys. 2013, 15, 17544. [CrossRef]

21. Grau, S.; Schilling, M.; Moonshiram, D.; Benet-Buchholz, J.; Luber, S.; Llobet, A.; Gimbert-Suriñach, C. Electrochemically and Photochemically Induced Hydrogen Evolution Catalysis with Cobalt Tetraazamacrocycles Occurs Through Different Pathways. ChemSusChem 2020, 13, 2745-2752. [CrossRef] [PubMed]

22. Roy, S.; Bacchi, M.; Berggren, G.; Artero, V. A Systematic Comparative Study of Hydrogen-Evolving Molecular Catalysts in Aqueous Solutions. ChemSusChem 2015, 8, 3632-3638. [CrossRef] [PubMed]

23. Yen, Y.-S.; Chen, W.-T.; Hsu, C.-Y.; Chou, H.-H.; Lin, J.T.; Yeh, M.-C.P. Arylamine-Based Dyes for p-Type Dye-Sensitized Solar Cells. Org. Lett. 2011, 13, 4930-4933. [CrossRef]

24. Cai, Y.; Meng, L.; Gao, H.; Guo, Z.; Zheng, N.; Xie, Z.; Zhang, H.; Li, C.; Wan, X.; Chen, Y. Achieving organic solar cells with efficiency over $14 \%$ based on a non-fullerene acceptor incorporating a cyclopentathiophene unit fused backbone. J. Mater. Chem. A 2020, 8, 5194-5199. [CrossRef]

25. Fujitsuka, M.; Sato, T.; Sezaki, F.; Tanaka, K.; Watanabe, A.; Ito, O. Laser flash photolysis study on the photoinduced reactions of 3,3'-bridged bithiophenes. J. Chem. Soc. Faraday Trans. 1998, 94, 3331-3337. [CrossRef]

26. Paa, W.; Yang, J.-P.; Rentsch, S. Intersystem crossing in oligothiophenes studied by fs time-resolved spectroscopy. Appl. Phys. B 2000, 71, 443-449. [CrossRef]

27. Massin, J.; Bräutigam, M.; Kaeffer, N.; Queyriaux, N.; Field, M.J.; Schacher, F.H.; Popp, J.; Chavarot-Kerlidou, M.; Dietzek, B.; Artero, V. Dye-sensitized PS-b-P2VP-templated nickel oxide films for photoelectrochemical applications. Interface Focus 2015, 5, 20140083. [CrossRef]

28. Reichardt, C.; Welton, T. Appendix A. Properties, Purification, and Use of Organic Solvents. In Solvents and Solvent Effects in Organic Chemistry; Wiley-VCH Verlag GmbH \& Co. KGaA: Weinheim, Germany, 2010; Volume 16, pp. 549-586. ISBN 9783527324736.

29. Montalti, M.; Credi, A.; Prodi, L.; Gandolfi, M.T. 9-Solvent Properties. In Handbook of Photochemistry; CRC Press (Taylor \& Francis Group): Boca Raton, FL, USA, 2006; Volume 3, pp. 535-559.

30. Ishow, E.; Guillot, R.; Buntinx, G.; Poizat, O. Photoinduced intramolecular charge-transfer dynamics of a red-emitting dicyanovinyl-based triarylamine dye in solution. J. Photochem. Photobiol. A Chem. 2012, 234, 27-36. [CrossRef]

31. Ishow, E.; Clavier, G.; Miomandre, F.; Rebarz, M.; Buntinx, G.; Poizat, O. Comprehensive investigation of the excited-state dynamics of push-pull triphenylamine dyes as models for photonic applications. Phys. Chem. Chem. Phys. 2013, 15, 13922. [CrossRef]

32. Flender, O.; Scholz, M.; Klein, J.R.; Oum, K.; Lenzer, T. Excited-state relaxation of the solar cell dye D49 in organic solvents and on mesoporous $\mathrm{Al}_{2} \mathrm{O}_{3}$ and $\mathrm{TiO}_{2}$ thin films. Phys. Chem. Chem. Phys. 2016, 18, 26010-26019. [CrossRef]

33. Oum, K.; Lohse, P.W.; Klein, J.R.; Flender, O.; Scholz, M.; Hagfeldt, A.; Boschloo, G.; Lenzer, T. Photoinduced ultrafast dynamics of the triphenylamine-based organic sensitizer $\mathrm{D} 35$ on $\mathrm{TiO}_{2}, \mathrm{ZrO}_{2}$ and in acetonitrile. Phys. Chem. Chem. Phys. 2013, 15, 3906. [CrossRef] [PubMed]

34. Massin, J.; Bräutigam, M.; Bold, S.; Wächtler, M.; Pavone, M.; Muñoz-García, A.B.; Dietzek, B.; Artero, V.; Chavarot-Kerlidou, M. Investigating Light-Driven Hole Injection and Hydrogen Evolution Catalysis at Dye-Sensitized NiO Photocathodes: A Combined Experimental-Theoretical Study. J. Phys. Chem. C 2019, 123, 17176-17184. [CrossRef]

35. Muresan, N.M.; Willkomm, J.; Mersch, D.; Vaynzof, Y.; Reisner, E. Immobilization of a Molecular Cobaloxime Catalyst for Hydrogen Evolution on a Mesoporous Metal Oxide Electrode. Angew. Chem. Int. Ed. 2012, 51, 12749-12753. [CrossRef] [PubMed]

36. Rentsch, S.; Yang, J.P.; Paa, W.; Birckner, E.; Schiedt, J.; Weinkauf, R. Size dependence of triplet and singlet states of $\alpha$-oligothiophenes. Phys. Chem. Chem. Phys. 1999, 1, 1707-1714. [CrossRef]

37. Grebner, D.; Helbig, M.; Rentsch, S. Size-Dependent Properties of Oligothiophenes by Picosecond Time-Resolved Spectroscopy. J. Phys. Chem. 1995, 99, 16991-16998. [CrossRef]

38. Paa, W.; Yang, J.P.; Helbig, M.; Hein, J.; Rentsch, S. Femtosecond time-resolved measurements of terthiophene: Fast singlet-triplet intersystem crossing. Chem. Phys. Lett. 1998, 292, 607-614. [CrossRef]

39. Janssen, R.A.J.; Smilowitz, L.; Sariciftci, N.S.; Moses, D. Triplet-state photoexcitations of oligothiophene films and solutions. J. Chem. Phys. 1994, 101, 1787-1798. [CrossRef] 
40. Volchkov, V.V.; Ivanov, V.L.; Uzhinov, B.M. Induced intersystem crossing at the fluorescence quenching of laser dye 7-amino-1,3-naphthalenedisulfonic acid by paramagnetic metal ions. J. Fluoresc. 2010, 20, $299-303$. [CrossRef]

41. Takashima, H.; Kawahara, H.; Kitano, M.; Shibata, S.; Murakami, H.; Tsukahara, K. Metal ion-dependent fluorescent dynamics of photoexcited zinc-porphyrin and zinc-myoglobin modified with ethylenediaminetetraacetic acid. J. Phys. Chem. B 2008, 112, 15493-15502. [CrossRef]

42. Ji, S.; Zhao, J.; Donato, M.D.; Xing, Y.H.; Mahmood, Z.; Taddei, M.; Rehmat, N.; Bussotti, L.; Doria, S.; Guan, Q.; et al. Color-tunable delayed fluorescence and efficient spin-orbit charge transfer intersystem crossing in compact carbazole-anthracene-BODIPY triads employing the sequential electron transfer approach. J. Phys. Chem. C 2020, 124, 5944-5957. [CrossRef]

43. Weiss, E.A.; Ratner, M.A.; Wasielewski, M.R. Direct measurement of singlet-triplet splitting within rodlike photogenerated radical ion pairs using magnetic field effects: Estimation of the electronic coupling for charge recombination. J. Phys. Chem. A 2003, 107, 3639-3647. [CrossRef]

44. Dance, Z.E.X.; Mi, Q.; McCamant, D.W.; Ahrens, M.J.; Ratner, M.A.; Wasielewski, M.R. Time-resolved EPR studies of photogenerated radical ion pairs separated by p-phenylene oligomers and of triplet states resulting from charge recombination. J. Phys. Chem. B 2006, 110, 25163-25173. [CrossRef] [PubMed]

45. Colvin, M.T.; Ricks, A.B.; Scott, A.M.; Co, D.T.; Wasielewski, M.R. Intersystem crossing involving strongly spin exchange-coupled radical ion pairs in donor-bridge-acceptor molecules. J. Phys. Chem. A 2012, 116, 1923-1930. [CrossRef] [PubMed]

46. Wu, W.; Zhao, J.; Sun, J.; Guo, S. Light-harvesting fullerene dyads as organic triplet photosensitizers for triplet-triplet annihilation upconversions. J. Org. Chem. 2012, 77, 5305-5312. [CrossRef]

47. Huang, L.; Cui, X.; Therrien, B.; Zhao, J. Energy-funneling-based broadband visible-light-absorbing Bodipy-C 60 triads and tetrads as dual functional heavy-atom-free organic triplet photosensitizers for photocatalytic organic reactions. Chem. A Eur. J. 2013, 19, 17472-17482. [CrossRef] [PubMed]

48. Huang, D.; Zhao, J.; Wu, W.; Yi, X.; Yang, P.; Ma, J. Visible-light-harvesting triphenylamine ethynyl C60-BODIPY dyads as heavy-atom-free organic triplet photosensitizers for triplet-triplet annihilation Upconversion. Asian J. Org. Chem. 2012, 1, 264-273. [CrossRef]

49. Marroux, H.J.B.; Curchod, B.F.E.; Faradji, C.A.; Shuttleworth, T.A.; Sparkes, H.A.; Pringle, P.G.; Orr-Ewing, A.J. Spin Changes Accompany Ultrafast Structural Interconversion in the Ground State of a Cobalt Nitrosyl Complex. Angew. Chem. Int. Ed. 2017, 56, 13713-13716. [CrossRef]

50. McCusker, J.K.; Walda, K.N.; Magde, D.; Hendrickson, D.N. Picosecond Excited-State Dynamics in Octahedral Cobalt(III) Complexes: Intersystem Crossing versus Internal Conversion. Inorg. Chem. 1993, 32, 394-399. [CrossRef]

51. Jacques, P.-A.; Artero, V.; Pecaut, J.; Fontecave, M. Cobalt and nickel diimine-dioxime complexes as molecular electrocatalysts for hydrogen evolution with low overvoltages. Proc. Natl. Acad. Sci. USA 2009, 106, 20627-20632. [CrossRef]

52. Dietzek, B.; Pascher, T.; Sundström, V.; Yartsev, A. Appearance of coherent artifact signals in femtosecond transient absorption spectroscopy in dependence on detector design. Laser Phys. Lett. 2007, 4, $38-43$. [CrossRef]

53. Frisch, M.J.; Trucks, G.W.; Schlegel, H.B.; Scuseria, G.E.; Robb, M.A.; Cheeseman, J.R.; Scalmani, G.; Barone, V.; Petersson, G.A.; Nakatsuji, H.; et al. Gaussian 16, Revision A.02; Gaussian Inc.: Wallingford, CT, USA, 2016.

54. Hohenberg, P.; Kohn, W. Inhomogeneous Electron Gas. Phys. Rev. 1964, 136, B864-B871. [CrossRef]

55. Runge, E.; Gross, E.K.U. Density-Functional Theory for Time-Dependent Systems. Phys. Rev. Lett. 1984, 52, 997-1000. [CrossRef]

56. Becke, A.D. Density-functional thermochemistry. III. The role of exact exchange. J. Chem. Phys. 1993, 98, 5648-5652. [CrossRef]

57. Weigend, F. Accurate Coulomb-fitting basis sets for H to Rn. Phys. Chem. Chem. Phys. 2006, 8, 1057-1065. [CrossRef]

58. Dolg, M.; Wedig, U.; Stoll, H.; Preuss, H. Energy-adjusted ab initio pseudopotentials for the first row transition elements. J. Chem. Phys. 1987, 86, 866-872. [CrossRef]

59. Yanai, T.; Tew, D.P.; Handy, N.C. A new hybrid exchange-correlation functional using the Coulomb-attenuating method (CAM-B3LYP). Chem. Phys. Lett. 2004, 393, 51-57. [CrossRef] 
60. Tomasi, J.; Mennucci, B.; Cammi, R. Quantum Mechanical Continuum Solvation Models. Chem. Rev. 2005, 105, 2999-3094. [CrossRef]

61. Li, Y.; Hu, J.; He, G.; Zhu, H.; Wang, X.; Guo, Q.; Xia, A.; Lin, Y.; Wang, J.; Zhan, X. Influence of Thiophene Moiety on the Excited State Properties of Push-Pull Chromophores. J. Phys. Chem. C 2016, 120, 13922-13930. [CrossRef]

62. Labrunie, A.; Gorenflot, J.; Babics, M.; Alévêque, O.; Dabos-Seignon, S.; Balawi, A.H.; Kan, Z.; Wohlfahrt, M.; Levillain, E.; Hudhomme, P.; et al. Triphenylamine-Based Push-Pull $\sigma-C 60$ Dyad As Photoactive Molecular Material for Single-Component Organic Solar Cells: Synthesis, Characterizations, and Photophysical Properties. Chem. Mater. 2018, 30, 3474-3485. [CrossRef]

63. Oum, K.; Flender, O.; Lohse, P.W.; Scholz, M.; Hagfeldt, A.; Boschloo, G.; Lenzer, T. Electron and hole transfer dynamics of a triarylamine-based dye with peripheral hole acceptors on $\mathrm{TiO}_{2}$ in the absence and presence of solvent. Phys. Chem. Chem. Phys. 2014, 16, 8019. [CrossRef]

Publisher's Note: MDPI stays neutral with regard to jurisdictional claims in published maps and institutional affiliations.

(C) 2020 by the authors. Licensee MDPI, Basel, Switzerland. This article is an open access article distributed under the terms and conditions of the Creative Commons Attribution (CC BY) license (http://creativecommons.org/licenses/by/4.0/). 